\title{
Use of a Biofeedback Breathing App to Augment Poststress Physiological Recovery: Randomized Pilot Study
}

David Plans ${ }^{1,2}$, BA, MSc, PhD; Davide Morelli ${ }^{1,3}$, BSc, PhD; Stefan Sütterlin ${ }^{4,5}$, BSc, PhD; Lucie Ollis ${ }^{6}$, BSc, MSc; Georgia Derbyshire ${ }^{6}, \mathrm{BSc} ;$ Mark Cropley ${ }^{6}, \mathrm{BSc}, \mathrm{PhD}$

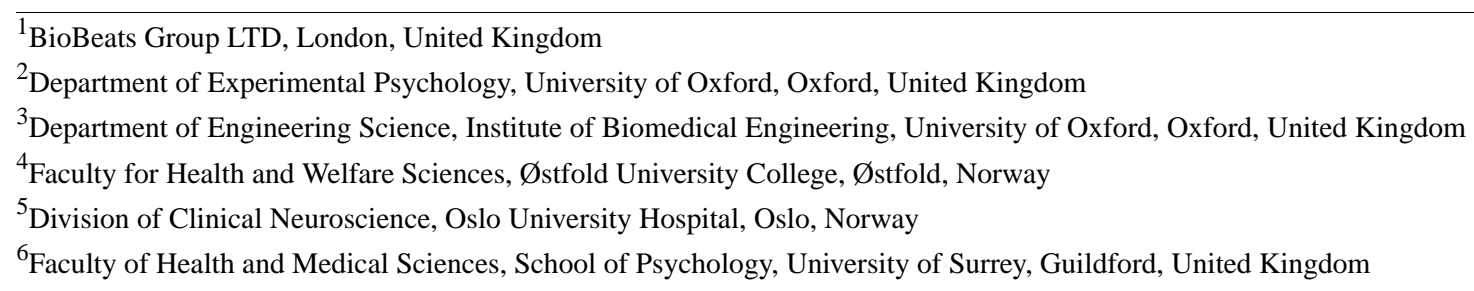

Corresponding Author:

Mark Cropley, BSc, PhD

Faculty of Health and Medical Sciences

School of Psychology

University of Surrey

School of Psychology

Stag Hill

Guildford, GU2 7XH

United Kingdom

Phone: 4401483686928

Email: mark.cropley@surrey.ac.uk

\begin{abstract}
Background: The speed of physiological recovery from stress may be a marker for cardiovascular disease risk. Stress management programs that incorporate guided breathing have been shown to moderate the stress response and augment recovery.

Objective: The aim of this study was to examine the effectiveness of an app-based brief relaxation intervention (BioBase) for facilitating physiological recovery in individuals exposed to a brief psychological stressor.

Methods: A total of 75 participants (44 women) completed a stressor speech task and were randomly assigned to one of three conditions: control, rumination, or an app-based relaxation breathing (BioBase) conditions. Heart rate variability (HRV) was assessed as a measure of autonomic function at baseline (6 min), during stress (6 min), and during recovery (6 min).

Results: There was a significant increase in subjective stress following stress exposure, but the ratings returned to baseline after recovery in all three groups. In addition, there was a significant decrease in vagally mediated HRV in the poststress period. During recovery, the root mean square of successive differences $(P<.001)$, the percentage of successive interbeat $(\mathrm{RR})$ intervals that differ by $>50 \mathrm{~ms}$ (pNN50; $P<.001)$, and high-frequency $(P<.02) \mathrm{HRV}$ were significantly higher in the BioBase breathing condition than the rumination and control conditions. There was no difference in HRV values between the rumination and control conditions during recovery.
\end{abstract}

Conclusions: App-based relaxed breathing interventions could be effective in reducing cardiovascular disease risk. These results provide additional utility of biofeedback breathing in augmenting physiological recovery from psychological stress.

(JMIR Formativ Res 2019;3(1):e12227) doi: 10.2196/12227

\section{KEYWORDS}

biofeedback; breathing; heart rate variability; recovery; rumination; stress 


\section{Introduction}

Cardiovascular disease is one of the leading causes of premature death and disability in most westernized countries and accounts for approximately $30 \%$ of deaths worldwide [1]. Its risk factors include genetic and congenital defects as well as behavioral factors such as diet, exercise, and smoking [2]. Another major risk factor for cardiac disease is mental stress [3,4]; mental stressors are known to cause physiological and psychological changes due to the activation of the sympathetic nervous system and parasympathetic withdrawal [5]. These changes include increased heart rate; respiration; and production of various biological stress markers including adrenaline, cortisol, and alpha-amylase. Prolonged stress exposure or delayed recovery from stress responses (ie, how quickly an individual returns to a specified resting baseline), is thought to contribute to cardiovascular disease risk, as it causes wear and tear of the cardiovascular system [6]. Growing research evidence suggests that recovery from stress may be more predictive of cardiovascular health than cardiovascular reactivity to the stressor itself [7-9].

Stress is a part of life and cannot be completely avoided. Therefore, it is crucial to identify and develop techniques that can augment recovery from stress in order to prevent the development of chronic health problems such as cardiovascular disease. One effective method for the management of stress is the use of biofeedback systems [10]. Biofeedback is a mind-body self-regulation practice, wherein individuals learn how to regulate their thoughts, feelings, and behavior to modify their physiology through continuous physiological feedback. For example, by instantaneously translating heart rate onto a visual display, an individual can quickly learn how slow breathing can be used effectively to reduce the heart rate. Biofeedback training has beneficial effects on many symptoms of stress, including anxiety and depression, and improves the overall health [11].

There are many different physiological stress markers such as elevated blood pressure, heart rate, and cortisol levels, but this study focused on heart rate variability (HRV). Changes in HRV have been shown to reflect levels of stress induced by a mental stressor [12,13]. In addition, HRV is a marker of autonomic dysfunction, and a reduced HRV has been associated with an increased risk of cardiovascular disease and mortality [14-16]. HRV is considered a nonintrusive, objective, discrete measure of vagally mediated cardiac regulation. Vagally mediated HRV refers to the beat-to-beat variability in heart rate that is controlled by the parasympathetic nervous system via the vagus nerve. Regulating emotions is a key life skill, and emotional changes appear to occur simultaneously with changes in HRV. Thus, HRV may be a marker of emotional regulation, which is activated when individuals are under mental stress [13,17-20]. The heart rate increases slightly during inspiration and decreases slightly during expiration; slow breathing evokes respiratory sinus arrhythmia, through which the heart rate and breathing synchronize, thereby increasing oscillations within the heart. Respiratory sinus arrhythmia is used as an index of cardiac vagal tone (referring to the activity of the vagus nerve) and contributes to HRV. Deep, slow diaphragmatic breathing stimulates the vagus nerve, thus improving HRV and reducing stress responses. By slowing down breathing, an individual can learn to control his/her heart rate and, ultimately, the HRV by increasing parasympathetic activity [21].

HRV biofeedback has resurged in recent years, and biofeedback interventions have been effective after an emotional disturbance [22]. In addition, interventions that include breathing exercises have been shown to reduce stress responsivity in both the laboratory and real world [23-25], although these interventions are time consuming and typically developed as part of a suite. For example, the body scan breathing exercise, which forms the basis of most mindfulness programs, requires repeated practice with typical sessions of $\geq 30$ min [25], whereas some studies that incorporate breathing routines require attendance in 10 treatment sessions, each lasting $90 \mathrm{~min}$ [24]. Such interventions, although effective, require investment of a lot of time from users, and many people feel time starved. Therefore, easy-to-use parsimonious interventions that mitigate the effects of stress are clearly advantageous. It is now possible for mobile health interventions to incorporate biofeedback breathing exercises in order to help people regulate their emotions during acute periods of stress.

Technology has paved the way and provided an easy and accessible method to engage with and monitor stress levels. Breathing techniques and biofeedback can now be easily combined to create an effective coping tool for stress management. Mobile technology can be used to effectively deliver stress-management techniques [26,27]. Through consumer-grade sensors, mobile phones provide an excellent avenue for collecting continuous biometric data such as those on heart rate and HRV. Such applications allow people to access their HRV biofeedback and modify their breathing, thereby gaining better control over stress [28]. Deep-breathing mobile phone apps are easy to use and inexpensive and have the potential to reach a large population; thus, they have far-reaching implications for long-term health.

This study aimed to examine a commercial breathing app called BioBase [29] as a potential intervention to reduce poststress activation. The BioBase program reduces stress responsivity by coaching users through Papworth breathing exercises, both audibly and visually. The regulation of breathing triggers a vagal response to aid parasympathetic activation, leading to relaxation.

To test the efficacy of the BioBase app, we subjected participants to a standard psychological stressor task and then randomly assigned them to one of three conditions: the BioBase breathing app, rumination, and control conditions. The rationale for using a rumination condition was amplification of possible differences in HRV between the three conditions. We hypothesized that compared to the rumination and control conditions, the Biobase breathing app would enhance recovery following exposure to a stressful speech task. 


\section{Methods}

\section{Participants}

A total of 75 participants were recruited to the study, including $44(59 \%)$ women and $31(41 \%)$ men, with an average age of 23.5 years (SD 6.39; range, 18-55 years). The sample predominantly identified themselves as white British $(\mathrm{n}=55$, $73 \%)$ and the remainder, as Asian $(n=8,11 \%)$, white other $(n=4$, $5 \%)$, African $(n=2,3 \%)$, black British $(n=1,1 \%)$, Greek $(n=1$, $1 \%)$, Hispanic $(\mathrm{n}=1,1 \%)$, mixed Hispanic $(\mathrm{n}=1,1 \%)$, and Mauritian $(n=1,1 \%)$. All participants received a $£ 15$ gift voucher for their time. The study was approved by the ethics committee of the University of Surrey, UK, and written informed consent was obtained from all participants (identifier: 1190-PSY-16).

\section{Speech Task}

During the stressor phase of the study, participants listened to a 2-min audio recording that described a situation where they had been falsely accused of stealing a purse and had to defend themselves to the police; this stressor has been used in previous studies (eg, [30]). The participants were instructed to imagine themselves in the scenario and were given 2 min to mentally think and prepare a statement for their defense in front of a video recorder. The recording stated that their speech would be evaluated and marked by the experts for fluency and confidence. This aimed to instill a social evaluative threat that has been shown to increase stress and rumination and induce physiological reactivity [31,32]. However, in reality, the speeches were not evaluated, as the performance ratings were not relevant to this study.

\section{BioBase App}

Participants in the BioBase condition were guided through a clinically validated version of the Papworth-Benson breathing exercise [33]. Originally developed at Papworth Hospital in Cambridgeshire, UK, more than 5 decades ago, this breathing method focuses on diaphragmatic breathing to use the full lung capacity and slow down breathing as well as trigger vagus nerve stimulation and consequently, the relaxation response. Through the process of photoplethysmogram and the use of the camera and flash on the mobile phone, the app measured changes in the user's heart rate during a guided breathing exercise and displayed their heart wave on the mobile phone screen in real time. Participants in the control and rumination conditions used a modified version of the Biobase app during the intervention period, which measured their heart rate, but did not guide them through the breathing exercise.

\section{Self-report measures}

\section{Thoughts Questionnaire}

Following a stress-exposure task, individuals may spontaneously ruminate [34] and therefore confound the results. To assess poststress rumination, we used a modified version of the Thoughts Questionnaire [35]. Items were rated on a 5-point scale, from 0 (never) to 4 (very often), on how often they thought about each item during the intervention period (eg, I made a fool of myself and how awkward I felt). The Thoughts Questionnaire has good internal consistency [36] and has been used in many previous studies to assess postevent rumination following the delivery of a speech task [32,37,38]. Cronbach's alpha for this measure was .81 in the present study.

\section{Heart Rate Variability}

HRV was captured during baseline, the speech task stressor, and poststress recovery by using a Biopac ECG100C amplifier (Biopac Systems Inc, Santa Barbara, CA). The electrocardiogram was recorded with a sampling rate of 1000 $\mathrm{Hz}$.

\section{Procedure}

After entering the laboratory, participants were asked to read the information sheet explaining the study. After providing written consent, the participants completed a demographic questionnaire. They were subsequently fitted with electrodes and acclimatized to the Biopac amplifier. The Biopac amplifier recorded heart data continuously throughout the experiment. All participants then relaxed for 6 min while the experimenter left the room to minimize distraction. On resuming the exercise, the participants rated their level of stress using a 7-point visual analogue scale (1, very little pressure to 7 , extreme pressure). Thereafter, the participants listened to the audio stressor recording for $2 \mathrm{~min}$, as described above in the Speech Task section, and were given 2 min to prepare a statement for their defense. They then presented their statement for $3 \mathrm{~min}$ in front of the experimenter and a video camera. Subsequently, the participants rated their level of stress using the 7-point stress scale. Following the speech task, participants were randomly assigned using a random number-generator program [39] to one of the three groups (control, BioBase, or rumination) for $6 \mathrm{~min}$. As this study was not a preregistered randomized controlled trial, it was considered a pilot study.

Participants assigned to the breathing condition used the BioBase app on the mobile phone and followed the guided breathing instructions. Individuals in the rumination condition were asked to think and reflect about their speech and focus on performance-based thoughts and were guided during this task by a modified version of the Thoughts Questionnaire [35]. Participants in the control condition were asked to sit passively. At the end of the intervention period, participants rated their level of stress. All participants then completed the original Thoughts Questionnaire [35] to measure the actual levels of rumination during the intervention phase. Finally, participants were disconnected from the equipment, fully debriefed, and given a gift voucher.

\section{Data Analysis}

All data were screened for measurement artifacts using the ARTiiFACT software [40] by one of the authors (SS) who was blinded to the conditions. Artifacts were identified using the algorithm developed by Berntson and colleagues [41], and a distribution-based threshold value calculated individually for each participant. Flagged beat intervals were visually checked and, if confirmed as artifacts, deleted and substituted by means of cubic spline interpolation of neighboring intervals. HRV analysis is typically performed in time or frequency domains. The time-domain measure root mean square successive difference (RMSSD) is considered to indicate vagally mediated 
HRV; values < $50 \mathrm{~ms}$ are considered unhealthy, values $>100$ are considered healthy, and values in between indicate risk. The frequency-domain analysis high frequency $(\mathrm{HF})$, which is considered to depict parasympathetic regulation, was also calculated for each person. Measurements and analyses followed established guidelines [42]. For the analysis, we grouped the HRV data into baseline, stressor, and intervention groups and analyzed 6-min segments, which are sufficient for HRV analysis [43]. Following the standard procedure, data were screened, outliers above and below 3 SDs were excluded, and data were transformed where necessary.

\section{Results}

There was no significant difference between the groups with regard to demographic variables (gender, physical fitness, smoking status, general stress, and age), any baseline measures of subjective stress, or HRV. Ratings of perceived stress significantly increased from baseline (mean $=2.01$, SD 0.97) following completion of the stressor (mean=5.05, SD 1.37; $t=18.68, \quad P<.001)$, demonstrating successful experimental manipulation. Perceived stress returned to baseline levels in all three groups at the end of the recovery period. From the baseline period to the stress period, there was a significant increase in the heart rate $($ mean $=78.59$, SD 10.90 to mean=88.10; SD 13.25; $t=-8.60 ; P<.001)$ and a significant decrease in the RMSSD (mean=44.13, SD 22.84 to mean $=40.09$, SD 15.56; $t=1.72$; $P=.04)$, percentage of successive interbeat (RR) intervals that differ by $>50 \mathrm{~ms}$ (pNN50; mean=17.75, $\mathrm{SD}=15.56$ to mean=13.46, $\mathrm{SD}=11.18 ; t=3.35, P<.001)$, and $\mathrm{HF}$ (mean=2.77, $\mathrm{SD}=0.42$ to mean=2.67, $\mathrm{SD}=0.37 ; t=2.42 ; P=.01$; one-tailed), demonstrating autonomic activation in response to stress. There were no main effects of interaction or group. However, there was a significant difference between groups $\left(F_{1,2}=10.46\right.$; $P<.001)$ in poststress rumination: The rumination group reported greater rumination (mean $=1.97, \mathrm{SD} 0.58)$ than the BioBase (mean=1.44, SD 0.79) and control (mean=1.37, SD 0.43) groups. There was no significant difference between the BioBase and the control groups in terms of poststress ruminative thoughts. Thus, the intervention manipulation was successful.

\section{Cardiac Analysis}

To examine the effects of the intervention on cardiac recovery in the poststress period, a between-subjects analysis of covariance for group (Biobase, rumination, and control) was conducted using the recovery measures as the outcome and the reactivity change score as a covariate. As individual differences in stress response could influence the findings, following previous research [9], we treated reactivity as a covariate to statistically remove the influence of reactivity on recovery. Apart from heart rate, a significant effect of group, with medium-to-large effect size, was found for RMSSD, pNN50, and HF. In addition, in all cases, the recovery rate was higher in the BioBase group than in the rumination and control groups. There were no significant differences between the rumination and control groups. Thus, individuals who used the breathing app demonstrated enhanced recovery from stress. The results of the analysis are presented in Table 1.

Table 1. Results of the data analysis. Values on each line with an astericks $(*)$ or dagger ( $\dagger)$ were not significantly different from one another.

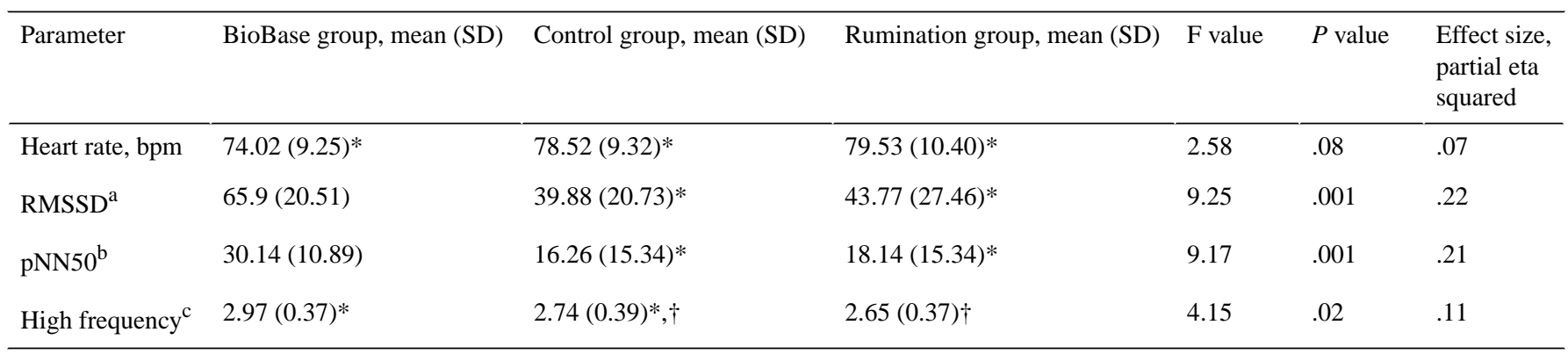

${ }^{\mathrm{a}} \mathrm{RMSSD}$ : root mean square successive difference.

${ }^{b}$ pNN50: percentage of successive inter-beat RR intervals that differ by $>50 \mathrm{~ms}$.

${ }^{\mathrm{c}}$ Log transformed.

\section{Discussion}

\section{Principal Findings}

As stress is an unavoidable part of life and the workplace becomes increasingly pressured, providing fewer opportunities for recovery, it is important to identify easy-to-use practical aids that can help individuals unwind and recover after the stressful period. The main finding of this study was that physiological recovery following stress exposure was enhanced in individuals who were guided through the BioBase breathing condition. This is an interesting finding because higher HRV is associated with reduced cardiovascular risks and other health outcomes [18,20,44].
We examined the effects of rumination on recovery in this study. Cognitive rumination has been defined as repetitive and intrusive negative thinking about past stressor(s) [45], and rumination is one of the main contributing factors that disrupts poststress recovery [46,47]. We were successful in manipulating rumination in the laboratory; however, rumination in the present study was not associated with reduced HRV, as there was no significant difference in poststress recovery between the rumination and control groups (as compared to [48]), although both groups showed reduced HRV as compared to the BioBase group.

Although there was a difference between the groups with respect to physiological parameters during recovery, there was no difference in subjective stress, as the levels of perceived stress 
returned to baseline for all groups in the recovery period. This finding is intriguing and suggests that perceptions of and actual physiology are not always in accordance. Individuals may think they have recovered from the effects of stress but may be unaware of their actual physiological state. This may not be an issue in the short term, but a mismatch between one's psychological and physiological state could lead to long-term health issues over time, especially in individuals who are exposed to high levels of stress or work in demanding jobs. Interventions aimed at increasing sensitivity to one's internal body state-perhaps, by enhancing interoceptive awareness - are needed. Somatic, or interoceptive awareness, could be defined as one's perceptual awareness of signals from the inside the body, such as heartbeats, breathing, bowel movements, and higher-order processes including beliefs and attitudes as well as emotions regarding those perceptions [49-51]. Interoceptive awareness can be measured and trained. Such training might rely on the fact that simply noticing feelings, particularly bodily sensations associated with particular feelings, can foster emotional regulation. This is an aspect of mindfulness training that has been previously explored in studies of meditation training on interoception [52,53]. In the future, studies should focus on the integration of multimodal systems such as digital screen-based devices (mobile phones) and multidimensional theoretical models of interoception that take into account measurement of autonomic nervous system disruption using HRV data in order to build multimodal, digital therapeutic systems that measure interoception as well as offer training experiences that might help manage anxiety-based disorders embedded in apps such as BioBase.

\section{Limitations}

There are some caveats with this present study. Heart rate monitoring was stopped after $6 \mathrm{~min}$; therefore, we do not know how long the actual effect on HRV lasted. It will be of interest for future studies to establish the benefits of guided breathing over time and examine whether the effect fades, stabilizes, or increases with repetition. Repeated use of the guided breathing app may help individuals who chronically experience stress to recover more quickly physiologically and improve their health outcomes and functioning. Although physical fitness has been associated with enhanced physiological recovery from stress [7,54], we did not assess the levels of physical fitness in this study, which could be perceived as a limitation. However, there was no significant difference between the groups in terms of self-reported physical activity, and therefore, it seems extremely unlikely that physical fitness could account for the difference between the conditions in HRV recovery. Nonetheless, future research should control for levels of fitness to completely rule out the possibility that fitness played a key role in our findings.

\section{Conclusions}

Given the ubiquitous nature of stress and the documented evidence associating stress with cardiovascular disease and mortality, it is important to identify affordable and practical aids that help individuals unwind and recover after the stressful period. To our knowledge, this is the first study to examine the effects of the BioBase breathing app on HRV under controlled conditions and provide evidence for its efficacy in aiding poststress recovery. These findings also provide evidence of the utility of biofeedback breathing in augmenting physiological recovery and suggest that app-based breathing interventions are effective in reducing cardiovascular disease risk.

\section{Acknowledgments}

Editorial noticeThis randomized study was non-registered. The editor granted an exception from ICMJE rules mandating prospective registration of randomized trials, because the risk of bias appears low and the study was considered formative, guiding the development of the application. However, readers are advised to carefully assess the validity of any potential explicit or implicit claims related to primary outcomes or effectiveness.

\section{Conflicts of Interest}

DP, DM, and LO are employees of a commercial company, BioBeats Group Ltd, London, UK. The other authors declare that the research was conducted in the absence of any commercial or financial relationships that could be construed as a potential conflict of interest.

\section{References}

1. Mozaffarian D, Benjamin EJ, Go AS, Arnett DK, Blaha MJ, Cushman M, American Heart Association Statistics CommitteeStroke Statistics Subcommittee. Heart disease and stroke statistics--2015 update: a report from the American Heart Association. Circulation 2015 Jan 27;131(4):e29-322. [doi: 10.1161/CIR.0000000000000152] [Medline: 25520374]

2. Schneiderman N, Ironson G, Siegel SD. Stress and health: psychological, behavioral, and biological determinants. Annu Rev Clin Psychol 2005;1:607-628 [FREE Full text] [doi: 10.1146/annurev.clinpsy.1.102803.144141] [Medline: 17716101]

3. Steptoe A, Kivimäki M. Stress and cardiovascular disease. Nat Rev Cardiol 2012 Apr 03;9(6):360-370. [doi: 10.1038/nrcardio.2012.45] [Medline: 22473079]

4. Kivimäki M, Kawachi I. Work Stress as a Risk Factor for Cardiovascular Disease. Curr Cardiol Rep 2015 Sep;17(9):630 [FREE Full text] [doi: 10.1007/s11886-015-0630-8] [Medline: 26238744]

5. Grippo AJ, Johnson AK. Stress, depression and cardiovascular dysregulation: a review of neurobiological mechanisms and the integration of research from preclinical disease models. Stress 2009 Jan;12(1):1-21 [FREE Full text] [doi:

10.1080/10253890802046281] [Medline: 19116888 ] 
6. McEwen B. Stress, adaptation, and disease: Allostasis and allostatic load. Ann N Y Acad Sci 1998 May;840(1):33-44. [Medline: 9629234$]$

7. Hocking Schuler JL, O'Brien WH. Cardiovascular recovery from stress and hypertension risk factors: A meta-analytic review. Psychophysiology 1997 Nov;34(6):649-659. [doi: 10.1111/j.1469-8986.1997.tb02141.x] [Medline: 9401420]

8. Kivimäki M, Leino-Arjas P, Kaila-Kangas L, Luukkonen R, Vahtera J, Elovainio M, et al. Is incomplete recovery from work a risk marker of cardiovascular death? Prospective evidence from industrial employees. Psychosom Med 2006;68(3):402-407. [doi: 10.1097/01.psy.0000221285.50314.d3] [Medline: 16738071]

9. Key BL, Campbell TS, Bacon SL, Gerin W. The influence of trait and state rumination on cardiovascular recovery from a negative emotional stressor. J Behav Med 2008 Jun;31(3):237-248. [doi: 10.1007/s10865-008-9152-9] [Medline: 18350377]

10. Kennedy L, Parker SH. Biofeedback as a stress management tool: a systematic review. Cogn Tech Work 2018 May 29. [doi: $10.1007 / \mathrm{s} 10111-018-0487-\mathrm{x}$ ]

11. Schoenberg PLA, David AS. Biofeedback for psychiatric disorders: a systematic review. Appl Psychophysiol Biofeedback 2014 Jun;39(2):109-135. [doi: 10.1007/s10484-014-9246-9] [Medline: 24806535]

12. Taelman J, Vandeput S, Spaepen A, Van Huffel S. Influence of Mental Stress on Heart Rate and Heart Rate Variability. In: ECIFMBE 2008, IFMBE Proceedings. Berlin: Springer; 2009 Presented at: 4th European Conference of the International Federation for Medical and Biological Engineering. Springer, Berlin, Heidelberg; .?1369; 2008; Berlin p. 1366-1369. [doi: 10.1007/978-3-540-89208-3 324]

13. Appelhans BM, Luecken LJ. Heart rate variability as an index of regulated emotional responding. Review of General Psychology 2006;10(3):229-240. [doi: 10.1037/1089-2680.10.3.229]

14. Singh JP, Larson MG, Tsuji H, Evans JC, O'Donnell CJ, Levy D. Reduced heart rate variability and new-onset hypertension: insights into pathogenesis of hypertension: the Framingham Heart Study. Hypertension 1998 Aug;32(2):293-297. [Medline: 9719057]

15. Thayer JF, Yamamoto SS, Brosschot JF. The relationship of autonomic imbalance, heart rate variability and cardiovascular disease risk factors. Int J Cardiol 2010 May 28;141(2):122-131. [doi: 10.1016/j.ijcard.2009.09.543] [Medline: 19910061]

16. Hillebrand S, Gast KB, de Mutsert R, Swenne CA, Jukema JW, Middeldorp S, et al. Heart rate variability and first cardiovascular event in populations without known cardiovascular disease: meta-analysis and dose-response meta-regression. Europace 2013 May;15(5):742-749. [doi: 10.1093/europace/eus341] [Medline: 23370966]

17. Heponiemi T, Ravaja N, Elovainio M, Näätänen P, Keltikangas-Järvinen L. Experiencing positive affect and negative affect during stress: relationships to cardiac reactivity and to facial expressions. Scand J Psychol 2006 Oct;47(5):327-337. [doi: 10.1111/j.1467-9450.2006.00527.x] [Medline: 16987201$]$

18. Thayer JF, Lane RD. Claude Bernard and the heart-brain connection: further elaboration of a model of neurovisceral integration. Neurosci Biobehav Rev 2009 Feb;33(2):81-88. [doi: 10.1016/j.neubiorev.2008.08.004] [Medline: 18771686$]$

19. Geisler FC, Vennewald N, Kubiak T, Weber H. The impact of heart rate variability on subjective well-being is mediated by emotion regulation. Personality and Individual Differences 2010 Nov;49(7):723-728. [doi: 10.1016/j.paid.2010.06.015]

20. Forkmann T, Meessen J, Teismann T, Sütterlin S, Gauggel S, Mainz V. Resting vagal tone is negatively associated with suicide ideation. J Affect Disord 2016 Apr;194:30-32. [doi: 10.1016/j.jad.2016.01.032] [Medline: 26802504]

21. Van Diest I, Verstappen K, Aubert AE, Widjaja D, Vansteenwegen D, Vlemincx E. Inhalation/Exhalation ratio modulates the effect of slow breathing on heart rate variability and relaxation. Appl Psychophysiol Biofeedback 2014 Dec;39(3-4):171-180. [doi: 10.1007/s10484-014-9253-x] [Medline: 25156003]

22. Wheat AL, Larkin KT. Biofeedback of heart rate variability and related physiology: a critical review. Appl Psychophysiol Biofeedback 2010 Sep;35(3):229-242. [doi: 10.1007/s10484-010-9133-y] [Medline: 20443135]

23. Hülsheger UR, Feinholdt A, Nübold A. A low-dose mindfulness intervention and recovery from work: Effects on psychological detachment, sleep quality, and sleep duration. J Occup Organ Psychol 2015 Mar 22;88(3):464-489. [doi: 10.1111/joop.12115]

24. Perciavalle V, Blandini M, Fecarotta P, Buscemi A, Di Corrado D, Bertolo L, et al. The role of deep breathing on stress. Neurol Sci 2017 Mar;38(3):451-458. [doi: 10.1007/s10072-016-2790-8] [Medline: 27995346]

25. Querstret D, Cropley M, Fife-Schaw C. Internet-based instructor-led mindfulness for work-related rumination, fatigue, and sleep: Assessing facets of mindfulness as mechanisms of change. A randomized waitlist control trial. J Occup Health Psychol 2017 Apr;22(2):153-169. [doi: 10.1037/ocp0000028] [Medline: 27054503]

26. Villani D, Grassi A, Cognetta C, Toniolo D, Cipresso P, Riva G. Self-help stress management training through mobile phones: an experience with oncology nurses. Psychol Serv 2013 Aug;10(3):315-322. [doi: 10.1037/a0026459] [Medline: 23937091]

27. Uddin AA, Morita PP, Tallevi K, Armour K, Li J, Nolan RP, et al. Development of a Wearable Cardiac Monitoring System for Behavioral Neurocardiac Training: A Usability Study. JMIR Mhealth Uhealth 2016;4(2):e45 [FREE Full text] [doi: 10.2196/mhealth.5288] [Medline: 27106171]

28. Munster-Segev M, Fuerst O, Kaplan SA, Cahn A. Incorporation of a Stress Reducing Mobile App in the Care of Patients With Type 2 Diabetes: A Prospective Study. JMIR Mhealth Uhealth 2017 May 29;5(5):e75 [FREE Full text] [doi: 10.2196/mhealth.7408] [Medline: 28554881] 
29. BioBeats. BioBase: the guided wellbeing course URL: https://biobeats.com/biobase/ [accessed 2018-12-13] [WebCite Cache ID 74dWb0Mon]

30. Ghiadoni L, Donald AE, Cropley M, Mullen MJ, Oakley G, Taylor M, et al. Mental Stress Induces Transient Endothelial Dysfunction in Humans. Circulation 2000 Nov 14;102(20):2473-2478. [doi: 10.1161/01.CIR.102.20.2473]

31. Zoccola PM, Dickerson SS, Zaldivar FP. Rumination and cortisol responses to laboratory stressors. Psychosom Med 2008 Jul;70(6):661-667. [doi: 10.1097/PSY.0b013e31817bbc77] [Medline: 18606726]

32. Zoccola P, Dickerson S, Lam S. Emotion. 2012. Eliciting and maintaining ruminative thought: The role of social-evaluative threat URL: http://doi.org/10.1037/a0027349 [accessed 2018-12-12] [WebCite Cache ID 74c91ZEyX]

33. Benson H, Marzetta BR, Rosner BA, Klemchuk HM. Decreased blood-pressure in pharmacologically treated hypertensive patients who regularly elicited the relaxation response. The Lancet 1974 Feb;303(2852):289-291 [FREE Full text] [doi: 10.1016/S0140-6736(74)92596-3] [Medline: 4130474]

34. Glynn LM, Christenfeld N, Gerin W. The role of rumination in recovery from reactivity: cardiovascular consequences of emotional states. Psychosom Med 2002 Sep;64(5):714-726. [doi: 10.1097/01.PSY.0000031574.42041.23] [Medline: 12271102]

35. Edwards SL, Rapee RR, Franklin J. Postevent rumination and recall bias for a social performance event in high and low socially anxious individuals. Cognit Ther Res 2003 Dec;27(6):603-617. [doi: 10.1023/A:1026395526858]

36. Makkar SR, Grisham JR. Social anxiety and the effects of negative self-imagery on emotion, cognition, and post-event processing. Behav Res Ther 2011 Oct;49(10):654-664. [doi: 10.1016/j.brat.2011.07.004] [Medline: 21788011]

37. Rachman S, Grüter-Andrew J, Shafran R. Post-event processing in social anxiety. Behaviour Research and Therapy 2000 Jun;38(6):611-617. [doi: 10.1016/S0005-7967(99)00089-3]

38. Abbott MJ, Rapee RM. Post-event rumination and negative self-appraisal in social phobia before and after treatment. J Abnorm Psychol 2004 Feb;113(1):136-144. [doi: 10.1037/0021-843X.113.1.136] [Medline: 14992666]

39. Urbaniak G, Plous S. Research Randomizer (Version 4). URL: http://www.randomizer.org/[WebCite Cache ID 73D2Hq0hx]

40. Kaufmann T, Sütterlin S, Schulz SM, Vögele C. ARTiiFACT: a tool for heart rate artifact processing and heart rate variability analysis. Behav Res Methods 2011 Dec;43(4):1161-1170. [doi: 10.3758/s13428-011-0107-7] [Medline: 21573720]

41. Berntson GG, Quigley KS, Jang JF, Boysen ST. An Approach to Artifact Identification: Application to Heart Period Data. Psychophysiology 1990 Sep;27(5):586-598. [doi: 10.1111/j.1469-8986.1990.tb01982.x]

42. Task Force of the European Society of Cardiology, North American Society of Pacing and Electrophysiology. Heart rate variability: Standards of measurement, physiological interpretation, and clinical use. Eur Heart J 1996 Apr;17(3):354-381. [Medline: $\underline{8737210}$ ]

43. Shaffer F, Ginsberg JP. An Overview of Heart Rate Variability Metrics and Norms. Front Public Health 2017 Sep;5:258 [FREE Full text] [doi: 10.3389/fpubh.2017.00258] [Medline: 29034226]

44. van Ravenswaaij-Arts CMA. Heart Rate Variability. Ann Intern Med 1993 Mar 15;118(6):436. [doi: 10.7326/0003-4819-118-6-199303150-00008]

45. Cropley M, Millward Purvis L. Job strain and rumination about work issues during leisure time: A diary study. European Journal of Work and Organizational Psychology 2003 Sep;12(3):195-207. [doi: 10.1080/13594320344000093]

46. Zoccola PM, Dickerson SS. Assessing the relationship between rumination and cortisol: a review. J Psychosom Res 2012 Jul;73(1):1-9. [doi: 10.1016/j.jpsychores.2012.03.007] [Medline: 22691553]

47. Cropley M, Plans D, Morelli D, Sütterlin S, Inceoglu I, Thomas G, et al. The Association between Work-Related Rumination and Heart Rate Variability: A Field Study. Front Hum Neurosci 2017 Jan;11:27 [FREE Full text] [doi:

10.3389/fnhum.2017.00027] [Medline: 28197087]

48. Ottaviani C, Thayer JF, Verkuil B, Lonigro A, Medea B, Couyoumdjian A, et al. Physiological concomitants of perseverative cognition: A systematic review and meta-analysis. Psychol Bull 2016 Mar;142(3):231-259. [doi: 10.1037/bul0000036] [Medline: 26689087]

49. Bornemann B, Herbert BM, Mehling WE, Singer T. Differential changes in self-reported aspects of interoceptive awareness through 3 months of contemplative training. Front Psychol 2014 Jan;5:1504 [FREE Full text] [doi: 10.3389/fpsyg.2014.01504] [Medline: $\underline{25610410}$ ]

50. Craig AD. How do you feel? Interoception: the sense of the physiological condition of the body. Nat Rev Neurosci 2002 Aug;3(8):655-666. [doi: 10.1038/nrn894] [Medline: 12154366]

51. Mehling WE, Gopisetty V, Daubenmier J, Price CJ, Hecht FM, Stewart A. Body awareness: construct and self-report measures. PLoS One 2009 May;4(5):e5614 [FREE Full text] [doi: 10.1371/journal.pone.0005614] [Medline: 19440300]

52. Farb NAS, Segal ZV, Anderson AK. Mindfulness meditation training alters cortical representations of interoceptive attention. Soc Cogn Affect Neurosci 2013 Jan;8(1):15-26 [FREE Full text] [doi: 10.1093/scan/nss066] [Medline: 22689216]

53. Haase L, Thom NJ, Shukla A, Davenport PW, Simmons AN, Stanley EA, et al. Mindfulness-based training attenuates insula response to an aversive interoceptive challenge. Soc Cogn Affect Neurosci 2016 Jan;11(1):182-190 [FREE Full text] [doi: 10.1093/scan/nsu042] [Medline: 24714209]

54. Blumenthal JA, Emery CF, Walsh MA, Cox DR, Kuhn CM, Williams RB, et al. Exercise training in healthy type A middle-aged men: effects on behavioral and cardiovascular responses. Psychosomatic Medicine 1988;50(4):418-433. [doi: 10.1097/00006842-198807000-00009] 


\section{Abbreviations}

HF: high frequency

HRV: heart rate variability

M: mean

RMSSD: root mean square successive difference

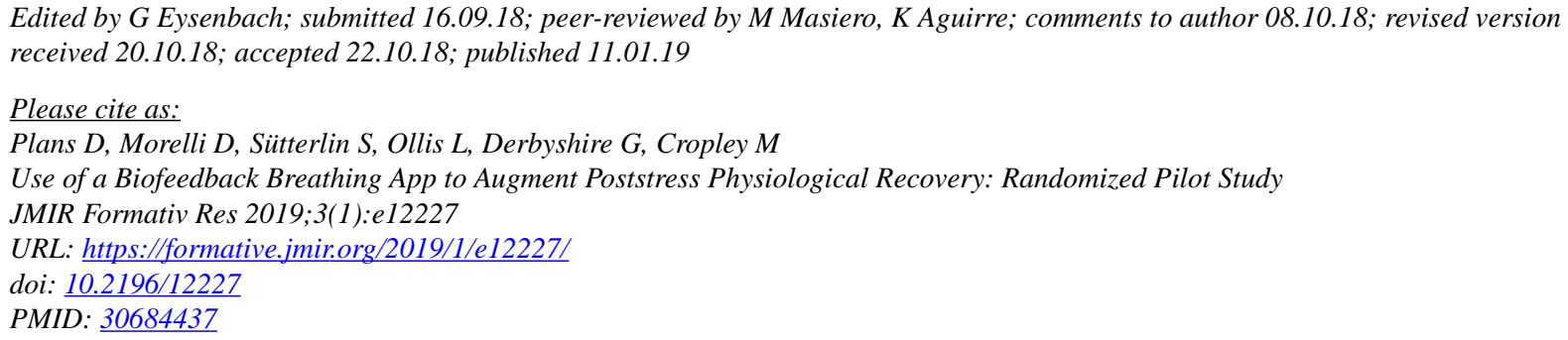

CDavid Plans, Davide Morelli, Stefan Sütterlin, Lucie Ollis, Georgia Derbyshire, Mark Cropley. Originally published in JMIR Formative Research (http://formative.jmir.org), 11.01.2019. This is an open-access article distributed under the terms of the Creative Commons Attribution License (https://creativecommons.org/licenses/by/4.0/), which permits unrestricted use, distribution, and reproduction in any medium, provided the original work, first published in JMIR Formative Research, is properly cited. The complete bibliographic information, a link to the original publication on http://formative.jmir.org, as well as this copyright and license information must be included. 